\title{
O PERÍODO SENGOKU E A CHEGADA DOS JESUÍTAS NO JAPÃO
}

Renata Cabral Bernabé

Resumo: O período que precedeu à chegada dos portugueses ao Japão, denominado período Sengoku, é caracterizado basicamente por instabilidade política, guerras contínuas e fragmentação do poder. Ao descrever os acontecimentos políticos do período, assim como a missão cristã (conduzida principalmente pelos jesuítas), este artigo busca entender a relação entre essa instabilidade do período sengoku e a inicial aceitação, por parte dos japoneses, de uma religião estrangeira.

Palavras-chave: Japão; jesuítas; período Sengoku; Cristianismo; missão.

\begin{abstract}
The period before the Portuguese arrival in Japan, called Sengoku period, is mainly described by its political instability, uninterrupted wars and power fragmentation. Meanwhile describing the political events of the period and the Christian mission (leaded mainly by the Jesuits), this article aims to understand the relationship between this sengoku period instability and the initial acceptance, by the Japanese, of a foreigner religion.
\end{abstract}

Keywords: Japan; Jesuits; Sengoku period; Christianity; mission.

\section{Introdução}

Os historiadores japoneses geralmente denominam o período que vai de 1467, ano do início da guerra de Ônin, até a entrada de Oda Nobunaga em Quioto em 1568, como período Sengoku - a era das províncias em guerra. Ele corresponde, aproximadamente, aos últimos cem anos do Muromachi Bakufu² (1333-1573).

1. Mestranda do departamento de História Social da FFLCH-USP.

2. Espécie de governo militar do Japão. 
Seu "subtítulo" não se deve ao acaso, a guerra de Ônin foi uma guerra civil longa e o período que se seguiu a ela foi extremamente conturbado e cheio de conflitos e batalhas. Além disso, suas consequências foram de extrema importância para a história do Japão.

Contudo, esse período não pode ser descrito apenas como um momento de colapso. Apesar da grande instabilidade política, foi um momento de formação de novas instituições e estruturas que iriam dar suporte a uma nova ordem, mais centralizada e poderosa que qualquer outra anterior na história do Japão, conhecida como Era Edo.

\section{A guerra civil de Ônin}

A Guerra de Ônin e Bunmei (mais conhecida apenas como Ônin) foi uma longa guerra civil que ocorreu entre os anos 1467 e 1477. Foi uma guerra que envolveu quase todas as casas de shugo-daimyō japonesas (espécie de "governadores" das províncias, nomeados pelo xogum ${ }^{3}$ ) e foi bastante destrutiva uma vez que foi lutada nas ruas da capital Quioto.

O motivo inicial dessa guerra foi uma disputa entre as famílias Hosokawa e Yamana pela escolha do herdeiro do xogum Ashikaga Yoshimasa. Este, segundo filho do assassinado Yoshinori, foi nomeado xogum em 1443, quando tinha apenas oito anos de idade. Como ainda era menor foi colocado sob a guarda do kanreiespécie de regente do xogum - Hosokawa Katsumoto. Yoshimasa foi declarado maior em 1449, com apenas quatorze anos.

No entanto, o bakufu, nesse momento, ainda não tinha se recuperado do choque causado pelo assassinato do antigo xogum (seu pai) em 1441. Além disso, o país não estava em uma boa situação econômica e Yoshimasa pouco (ou nada) fez para reverter o quadro e continuou ostentando muito luxo.

Em 1464 ele ainda não possuía herdeiros e acabou por convencer seu irmão mais novo, Ashikaga Yoshimi, a abandonar sua vida de monge para ser nomeado seu herdeiro. Contudo, em 1465 nasce o primeiro filho de Yoshimasa, Yoshihisa, o que causou desavenças entre os irmãos. Yamana Sôzen aproveitou-se da oportunidade para se opor à família Hosokawa e passou a defender Yoshihisa como herdeiro do xogum.

A guerra é deflagrada em 1467 e estoura justamente na capital Heian-kyô (atual Quioto). A disputa acerca da sucessão tornou-se um pretexto para uma busca pela supremacia militar e diversas casas de shugo-daimyō entraram no conflito. No fim, contudo, não houve vitoriosos. Os exércitos simplesmente cessaram suas

3. Comandante militar do Japão. No presente artigo utilizarei a grafia aportuguesada do termo e não sua transliteração para o alfabeto romano (shogun). 
campanhas pela exaustão. Ao fim da guerra a maioria dos shugo-daimyyô já havia deixado a capital e retornado para as suas províncias para consolidar ali suas forças. A capital já não era mais uma fonte de poder para eles. Iniciam-se, então, as diversas consequências imediatas dessa guerra. O poder se fragmentou e o bakufu perdeu bastante seu poder de governo.

\section{Pós Ônin}

Quando os shugo-daimyō retornaram às suas províncias viram que seus vassalos que lá residiam mostravam sinais de insubordinação. Sob tais circunstâncias nem todos sobreviveriam. Esse foi o maior impulso para o surgimento dos chamados sengoku-daimyō que se contrapunha ao shugo-daimyō, pois sua autoridade e legitimidade não provinham do bakufu (não eram nomeados pelo xogum), mas da sua habilidade em exercer o poder e manter o controle sobre os outros kokujin (senhores de terras menores, sem o status de daimyō) e comunidades de camponeses. No entanto, em alguns casos, para se legitimar, eles se declaravam sucessores dos antigos shugo-daimyō ou outros oficiais provinciais.

A ordem central, a partir de então, passou a ser desafiada por grupos e comunidades que queriam autonomia para lidar com questões locais. A prova disso foi a formação das ligas Ikki. Nelas, os kokujin provenientes de famílias locais de samurais (buke) uniam-se e tornavam-se proprietários únicos das suas terras, conseguindo proteger-se das autoridades centrais.

Essa maior inclinação à autoridade local foi evidente também nos níveis mais baixos da sociedade. Um dos aspectos que evidenciam isso foi a crescente liberdade outorgada pelas vilas agricultoras para se organizar de acordo com a vontade da comunidade. As autoridades tiveram de fazer diversas concessões a essas vilas que se utilizavam de organizações com vizinhas em demonstrações de massa para conseguir o que queriam.

Foi nesse contexto que os incipientes sengoku-daimyō reconheceram a necessidade de se adaptar às demandas dos camponeses e se declararam protetores de todas as classes dentro de seus domínios (kokka).

Contudo, embora essas mudanças estivessem ocorrendo nas províncias, seu verdadeiro impacto não alcançou a capital antes da metade do século XVI. A capital e as terras agriculturáveis que a cercavam, formavam uma região central que manteve sua própria configuração nesse período.

Além disso, o bakufu mesmo estando em declínio e tendo perdido muito de sua governabilidade, ainda tinha um papel a desempenhar e permaneceu com sua legitimidade reconhecida para governar. Apesar de alguns xoguns não terem poder pessoal algum, a família Hosokawa, que havia monopolizado o posto de kanrei, manteve certa estabilidade na região da capital. 


\section{A chegada dos jesuítas e a missão cristã}

Foi nesse contexto que os primeiros jesuítas chegaram ao Japão. Eles chegaram cerca de oito anos depois de três portugueses terem ido parar acidentalmente na ilha de Tanegashima, graças a um tufão que conduziu para lá a pequena embarcação na qual se encontravam. Era a primeira vez que europeus pisavam em solo japonês e pouco tempo depois (dois ou três anos) Portugal estabeleceu um lucrativo comércio com alguns dos daimyō japoneses, proprietários dos portos frequentados por eles.

Os primeiros jesuítas (pode-se dizer também os primeiros missionários cristãos) no Japão foram os padres Cosme de Torres e Francisco Xavier, acompanhados do irmão João Fernandez e de um pequeno grupo de japoneses conversos. Estes haviam se refugiado num navio português alguns anos antes e, levados a Goa conheceram Xavier que os evangelizou.

Quando estes missionários pisaram em solo japonês pouco sabiam da situação política vivida naquele momento no país. Assim que chegaram procuraram logo de início falar com o imperador para que este os autorizasse e auxiliasse na pregação. Não faziam idéia de que há séculos o imperador carregava apenas um poder simbólico e religioso, mas não político. Além disso, a chance de estrangeiros como eles ficarem face a face com uma figura tão sagrada, como era considerado o imperador, era praticamente nula.

Xavier descobriu isso após viajar para a capital Quioto em busca de uma audiência com o imperador e não conseguir sucesso. Ele já começara a entender um pouco da situação política assim que chegou. Isso porque o daimyō de Satsuma (região na qual ele aportara em 1549) os expulsou pouco tempo depois de ter-lhes dado autorização para a pregação, descontente com a ausência de barcos de mercadores portugueses nos seus domínios. Os missionários partiram então para Hirado onde são bem recebidos, graças a um navio português que ali aportara recentemente (JANEIRA, 1970).

Dessa maneira os missionários foram percebendo na prática como as questões funcionavam no arquipélago. A negociação com os daimyō das terras em que eles pregavam era constante e logo ficou clara a desestruturação do poder central. Mesmo assim eles perceberam que este ainda tinha uma função a cumprir. Os jesuítas acabaram, portanto, por entrar numa complicada trama de poderes a fim de receber aval e proteção das principais autoridades para que pudessem prosseguir a evangelização no país.

O desafio dos jesuítas, contudo, não se restringia a sua inicial ignorância da situação política japonesa de então. $O$ fato de não conhecerem a língua, os costumes e as religiões praticadas, constituiu a maior barreira a ser transposta. Logo de início, o tradutor do pequeno grupo de jesuítas foi Yajirô (também se encontra a grafia Anjirô), um dos japoneses que se convertera em Goa. Contudo, 
ele teve grandes dificuldades na tradução (talvez até mesmo de compreensão) de diversos termos cristãos. Além disso, ele informou mal os missionários acerca do Budismo praticado no Japão e chegou a equalizar o Deus cristão com Dainichi, uma força maior do Budismo Shingon (HALL, 1990). Resultado: Xavier iniciou a evangelização no Japão pregando Dainichi. $\mathrm{O}$ fato de os missionários terem, ainda, vindo da Índia, terra natal do Budismo, contribuiu para que a população local acreditasse que eles pregavam apenas mais uma seita budista. Foi somente em conversas posteriores com monges japoneses que Xavier percebeu seu erro e passou a pregar que Dainichi era uma invenção do diabo, o que obviamente provocou a antipatia de muitos budistas.

Xavier deixa o arquipélago em novembro de 1551 (um ano antes da sua morte). De lá ele vai para a Índia, de onde envia mais três padres (Baltazar Gago, Duarte da Silva e Pedro de Alcáçova) para reforçar a pequena e mais nova missão das Índias Orientais (HALL, 1990). No Japão, Cosme de Torres assumiu o cargo de primeiro Superior da missão japonesa.

Apesar de ter passado tão pouco tempo, Xavier em muito se entusiasmou com a nova missão. Seus relatórios sobre o Japão o demonstram claramente. Ele chega a afirmar que os japoneses eram as melhores pessoas dentre os ignorantes da fé cristã, encontrados até então (SAMSON, 1990). Além disso, mesmo com todas as dificuldades que enfrentaram, os missionários conseguiram um bom número de conversões. Para George B. Sansom é difícil falar em números para esses dois primeiros anos, mas o resultado pode ser visto como considerável (SAMSON, 1990).

O superiorato de Cosme de Torres no Japão se inicia, portanto, em 1551, com a partida de Xavier e acaba somente com a sua morte em 1570. Pode-se dizer que ainda compreende uma fase inicial da missão católica no Japão, muito embora ela tenha sido extremamente curta quando comparada com as missões na América, por exemplo. No entanto, naquele momento os missionários não tinham como saber disso e o Japão logo se tornou a grande aposta por parte dos jesuítas. Leon Bourdon afirma que a pequena missão era o carro-chefe da propaganda evangelizadora nos países da Ásia no século XVI (BOURDON, 1993).

Nos primeiros anos os missionários conseguiram converter um bom número de pessoas. No entanto, essas conversões ocorreram somente dentre a população pobre, a maioria camponeses, que muitas vezes eram atraídos pelas obras de caridade promovidas pelos jesuítas. As conversões extrapolaram para os daimyō, mas isso em anos posteriores. A historiografia consagra Omura Sumitada - batizado em 1563 com o nome de Bartolomeu - como o primeiro daimyō cristão. No entanto, se Sumitada possuía ou não, já em 1563, o status de daimyō é controverso (HALL, 1990).

Além de dom Bartolomeu de Omura (como aparece nas fontes jesuítas) outros daimyō se converteram, dentre eles podemos citar Otomo Sorin Yoshihige 
$\left(\right.$ Francisco ${ }^{4}$ ), seu segundo filho Chikaie (Sebastião), Arima Yoshisada (André) e Takayama Ukon (Justo).

A missão japonesa, até a chegada dos franciscanos em 1592, ficou sob o monopólio dos jesuítas. Estes, antes de chegar ao Japão, já haviam instalado missões em outros locais na Ásia; contudo, ali viveram mais integrados com a população local, em contraste com outras regiões onde acabaram desenvolvendo suas atividades mais à sombra das feitorias e fortes do "Estado da Índia" controlado pelos portugueses.

Sendo assim, o envolvimento que tiveram com a população nipônica, assim como com seus costumes, religiões e problemas políticos foi bastante diferenciado do que aconteceu na China ou Índia, por exemplo. O desenvolvimento da missão correu paralelamente ao desenvolvimento da situação política do país e uma vez que as mudanças naquele momento eram drásticas e constantes, na missão a situação não poderia ter sido diferente.

\section{A reunificação do Japão e o desenrolar da missão}

O processo de reunificação do Japão iniciara pouco tempo depois de os jesuítas chegarem ao arquipélago. Oda Nobunaga (1534-1582) foi o grande responsável por iniciar a reunificação. Filho de um daimyō pouco conhecido da província de Owari, adquiriu notável riqueza e poderio militar ao derrotar importantes daimyō através de hábeis estratégias militares.

Seu relacionamento com os missionários é sintomático desse processo. Isso porque em meio às batalhas que teve de enfrentar, Nobunaga se viu diversas vezes frente a frente com monastérios budistas que se aliavam a seus inimigos. O líder acabou, portanto, facilitando, por diversas vezes, o caminho dos missionários. Em 1569 recebeu-os pela primeira vez.

Ele jamais se converteu ao Cristianismo e não se pode dizer que fosse contra o Budismo em si. O fato é que ele não tolerava a interferência dos monges na política. Ao conceder aval para a pregação, terrenos ou proteção para os jesuítas ele procurava minar não a religião budista, mas o poder político alcançado pelos monges.

Por volta de 1560 a crise chega à capital novamente. O kanrei (espécie de "regente" do xogum) Hosokawa Ujitsuna fora expulso por antigos vassalos. Em 1565 esse mesmo grupo assassina o xogum Ashikaga Yoshiteru e o substitui por Yoshihide. O outro potencial sucessor, Ashikaga Yoshiaki, naquele momento um monge, escapou para o oeste em busca de apoio para sua causa. Foi Oda Nobunaga quem o apoiou. Ele consegue entrar em Quioto em 1568 (ano da morte de

4. Nome de batismo. 
Yoshihide) e assim que ele ganha o controle da cidade o imperador Ôgimachi nomeia Yoshiaki xogum. Apesar de seu poder político praticamente nulo o imperador ainda era o grande manto de legitimidade.

Nobunaga por sua vez não assume nenhum posto. Em 1573, entretanto, ele derrota Yoshiaki após descobrir que este enviara cartas a daimyō e instituições religiosas hostis a ele, chamando-os para uma intervenção militar, provavelmente temeroso do grande poderio que o líder vinha acumulando.

Com a queda de Yoshiaki o xogunato da família Ashikaga encontra seu fim. Nobunaga não assume o posto de xogum, mas pelo seu poderio militar ele era a figura mais proeminente do Japão, naquele momento. Como forma de legitimação da nova ordem política ele faz com que o imperador mude o nome da era para Tenshô (1572-1592) (YAMAMURA, 1990).

A historiografia denomina o período que compreende o xogunato Ashikaga como Muromachi Bakufu. O período seguinte é conhecido como Azuchi Momoyama, numa referência a dois castelos construídos no período. A periodização é bastante curta uma vez que o Azuchi Momoyama tem seu fim em 1603 (data da nomeação de Tokugawa Ieyasu a xogum). Trata-se na realidade de um momento de transição. Os dois famosos líderes do período, Oda Nobunaga e Toyotomi Hideyoshi, não foram nomeados xoguns por não possuírem nenhum parentesco com o clã imperial (ao contrário da família Ashikaga ou Minamoto, que assumiram o xogunato durante os dois governos militares anteriores à era Edo), mas tiveram um papel central no processo de reunificação.

A missão cristã, por sua vez, também passou por importantes mudanças no mesmo período. Em 1570 Cosme de Torres, Superior da missão, morre. Desde 1566 pensava-se em um possível sucessor para ele, pois idade e doença começavam a impedi-lo de desempenhar o seu cargo. Pero Ramirez, reitor do colégio de São Paulo em Goa, designou Antonio de Quadros como sucessor de Torres, mas este morre ao chegar ao Japão.

Francisco Cabral foi então o escolhido para assumir o cargo. Cabral era um homem que já possuía longa e múltipla experiência nas coisas do Oriente (BOURDON, 1993). Nascido em Covilhã era originário de uma província portuguesa. Em 1550 partiu para a Índia como soldado enviado do vice-rei dom Afonso de Noronha. Lá, contudo, acabou por abraçar a carreira eclesiástica e entrou para a Companhia de Jesus em 1554. Em junho de 1570 ele chega ao Japão para assumir o cargo de Superior. Cosme de Torres falece em outubro do mesmo ano.

É durante o seu superiorato que as polêmicas acerca da missão japonesa se inicia dentre os jesuítas. Cabral é descrito tanto por alguns de seus contemporâneos quanto por grande parte da historiografia atual como uma pessoa intransigente que pouco fez pelo engrandecimento da missão japonesa. O principal responsável por essa visão foi Alexandre Valignano, Visitador Geral das Índias Orientais de 1574 
até 1606 (ano de sua morte), que antagonizou com Cabral acerca das missões no oriente por todo o período que esteve lá.

Assim que Valignano chega ao Japão em 1579 resolve promover algumas "consultas", que seriam uma espécie de reunião dos jesuítas para discutirem os rumos da missão e aprimorarem seus métodos. As consultas são realizadas nos anos seguintes em Usuki, Azuchi e Nagasaki. Foi durante essas consultas que o antagonismo entre Valignano e Cabral ficou visível.

A grande polêmica acerca da missão japonesa que os opôs foi no tocante à forma que os missionários deveriam se comportar. Enquanto Valignano era enfático na sua defesa daquilo que ele chamou de accommodatio - ou seja, que os missionários deveriam adotar tantos costumes japoneses quanto fosse possível, para que se tornassem respeitados e compreensíveis para a população local-Cabral se opunha a tal idéia afirmando que tal conduta apenas resultaria no afrouxamento dos preceitos defendidos pela Companhia de Jesus e da doutrina cristã.

A princípio, com a renúncia de Cabral ao superiorato do Japão (alegando problemas de saúde ele pede para deixar o cargo e vai para Macau em 1581, Gaspar Coelho assume como Superior da missão [JANEIRA, 1970]) pode-se pensar que a proposta de Valignano foi vitoriosa. Contudo, a organização das missões no além-mar não segue uma lógica tão simples assim. Apesar de os jesuítas terem um código de conduta no qual a obediência aos superiores tem lugar destacado, quando se trata de missões tão distantes, tendo em conta a lenta comunicação da época, o arbítrio individual de cada missionário que atuava na missão precisa ser levado em conta. Além disso, nem mesmo o Geral da Ordem naquele momento, Pe. Cláudio Acquaviva, que ficava em Roma, demonstrou um total e irrestrito apoio às idéias de Valigano para o Japão.

É inegável, entretanto, que após a saída de Cabral as idéias do Visitador para o Japão prevaleceram. A redação do Regimento para os Padres que estão nas residências de Japão, feito ultimamente pólo Pe. Visitador no mes de Novembre no anno de 1581 é apenas um dos exemplos desse processo. Tal regimento gerou muita polêmica e Valignano teve inclusive que se justificar a Roma por causa dele. Contudo, ele era a maior autoridade dentre os jesuítas no Oriente e até que se recebesse outra ordem do Geral em Roma, era a sua palavra que deveria ser obedecida (TALADRIZ, 1954).

Não se pode dizer, contudo, que Valignano tenha inovado completamente a estratégia de evangelização dos jesuítas ao propor a accommodatio. A "utilização de elementos da cultura nativa como 'linguagem' para veicular conteúdos da fé católica" (POMPA, 2003) já fazia parte da pedagogia jesuítica. Durante o superiorato de Cosme de Torres a estratégia de imitar alguns dos costumes japoneses para se fazerem compreendidos já era utilizada. Xavier já havia instruído a Torres que em tudo que não fosse culpável eles deveriam seguir os costumes japoneses (TALADRIZ, 1954). 
Torres, contudo, jamais sistematizou isso como uma regra, como Valignano posteriormente o fará. É difícil inclusive falar de estratégias sistematizadas para o Japão, antes de Valignano. Desde que chegaram ao Japão os missionários engajaram-se no aprendizado do idioma e das religiões nativas. Em 1555 foi compilado o Sumário dos erros en que os gentios do Japão vivem e de algumas seitas gentílicas en que principalmente confia pelos padres Cosme de Torres e Baltasar Gago. Contudo, tais estudos provinham muito mais de uma necessidade da prática diária colocada pela pregação.

Durante o superiorato de Cabral os estudos sobre a cultura e língua japonesas não avançaram muito. Valignano, anos mais tarde o acusará de negligenciar tal tipo de estudo. A sistematização de uma estratégia também não foi feita; no entanto, ao analisarmos os rumos da missão durante os onze anos do superiorato de Cabral, assim como seus escritos, podemos perceber que os métodos empregados pelo superior são fundamentados basicamente em dois pressupostos: um julgamento pessimista do caráter japonês e a ênfase na primazia das fontes sobrenaturais da missão (ELISON, 1973), ou seja, a idéia de que obedecendo aos ensinamentos de Cristo (como a humildade da vida apostólica, o poder da cruz, a confiança em Deus, etc.) a missão iria progredir. Na sua crítica a Valignano ele afirma que o Visitador coloca muito peso nas ações humanas e pouco nos desígnios divinos ${ }^{5}$. Valignano responde, por sua vez, que "o recurso às armas humanas era consequência do silêncio do Deus" (PROSPERI, 1994: 157).

O antagonismo de ambos não finda com a saída de Cabral do Japão. Eles continuam a divergir não apenas acerca do modo de proceder na missão, mas também quanto ao grau de subordinação do vice-provincial do Japão ao provincial da Índia, a taxação de cada colégio e casa da província e suas vice-províncias, entre outros. Anos mais tarde, numa correspondência com o Padre Geral da Ordem em 1593 e em 1595, ambos retomam as desavenças do tempo em que Cabral era Superior do Japão, acrescentando ainda novas discordâncias.

\section{O fim da reunificação e a decadência da missão}

A realidade, entretanto, é que a situação dos missionários no Japão vai ficando cada vez mais complicada. Em 1582 Nobunaga é assassinado por um de seus generais. Nesse momento mais da metade das províncias do Japão estavam sob seu poder, sendo estas as mais importantes estrategicamente uma vez que se encontravam agrupadas ao redor da capital (SAMSON, 1973). Sua situação, no entanto, não era inexpugnável. Numa aliança com Tokugawa Ieyasu, Toyotomi

5. Francisco Cabral. Carta enviada ao Pe Geral da Cia. Claudio Acquaviva. 15 de dezembro de 1593. In: WICKI S.J., Joseph; GOMES S.J., John (eds.). Documenta Indica (1592-1594), v. XVI, Roma: Institutum Historicum Societatis Iesu, 1984. 
Hideyoshi assume a liderança, é nomeado kanpaku (uma espécie de regente de um imperador já adulto), e continua a obra de reunificação do Japão iniciada por Nobunaga.

Inicialmente Hideyoshi mantém boas relações com os missionários cristãos. Em 1583 ele recebe o Superior da missão de Miyako ${ }^{6}$, o Pe. Organtino Gnecchi Soldo, e lhe dá um terreno em Osaka para construção de uma igreja. Contudo, sem qualquer aviso prévio Hideyoshi baixa, em 1587, um edito ordenando a todos os daimyō que expulsem os jesuítas de seus domínios. Os territórios concedidos aos missionários até aquela data são confiscados pelo líder.

Tal decreto pegou a todos de surpresa, pela primeira vez em séculos o poder central tomava medidas restritivas quanto às atividades de estrangeiros (YAMASHIRO, 1989). Mesmo assim ele não foi levado muito a sério. Os missionários não diminuíram suas atividades no Japão, apenas passaram a fazê-la mais discretamente. Hideyoshi por sua vez também não promoveu qualquer perseguição a não ser pelos confiscos das terras.

Em 1590 ele termina a reunificação japonesa. Com todas as províncias do arquipélago sob seu poder, Hideyoshi se confirma como único líder.

Os jesuítas, por sua vez, sofrem outro revés em 1592, quando franciscanos espanhóis vão das Filipinas para o Japão e iniciam lá a sua pregação. Os métodos de adaptação utilizados pelos jesuítas são colocados em questão pelos franciscanos que pouco sabiam do contexto e costumes japoneses. Tal divergência entre as ordens acaba transparecendo para os japoneses e colocando em xeque a visão de um Cristianismo único e sem polêmicas, ensinada pelos jesuítas até então. Além disso, os franciscanos pregavam abertamente o que chamou a atenção das autoridades que vinham até o momento tolerando a atuação dos jesuítas, mesmo proibidos.

Irritado com a situação Hideyoshi confisca a nau espanhola San Felipe em 1596. Os seis sacerdotes que estavam a bordo são enviados a Nagasaki e lá são executados com outros vinte cristãos japoneses. Esse é o primeiro martírio cristão no Japão.

A partir daí a situação só piora para os japoneses conversos e missionários. Com a morte de Hideyoshi em 1598 e a subida ao poder de Tokugawa Ieyasu a perseguição aumenta e o número de cristãos vai cada vez mais decrescendo. A revolta de Shimabara - uma rebelião camponesa com alta participação de cristãos em 1637 - é tida pela historiografia como marco do fim do século cristão no Japão. Isso porque depois dela o isolamento do país se intensificou com a chamada política do sakoku. Os europeus, com exceção dos holandeses (que também so-

6. A missão no Japão era dividida em três partes: Miyako - correspondente a região da capital - Bungo e Shimo. Cada uma das três partes possuía um Superior, que era subordinado ao Superior universal do Japão. 
freram restrições), foram proibidos de frequentar qualquer porto do arquipélago e os japoneses são proibidos de deixar o país.

Para além de toda a polêmica gerada entre os missionários a respeito da evangelização do povo japonês - seja entre as ordens cristãs ou dentre os jesuítas - a total extirpação do cristianismo do solo japonês, assim como de qualquer outra influência ocidental, diz muito mais respeito à conjuntura interna ao Japão do que à política missionária adotada pelos europeus.

Em 1600 ocorre a famosa batalha de Sekigahara, cujo desfecho confirma a supremacia do clã Tokugawa que irá governar o país pelos próximos 268 anos. Hideyoshi, que morreu na Coreia em 1598, não conseguiu passar à sua família a liderança. Seu antigo aliado, Tokugawa Ieyasu, após abater o clã Toyotomi em Sekigahara, é nomeado xogum em 1603 e tem início a Era Edo (ou Tokugawa Bakufu).

\section{Conclusão}

O Japão da Era Edo, em contraste com o período anterior (Azuchi-Momoyama), é uma cultura sob isolamento. A secularização do curso da vida assim como a racionalização da autoridade política iam de encontro à doutrina cristã. Para George Elison "o Cristianismo não poderia prevalecer, era incompatível com os objetivos da reconstrução do início do período moderno" (ELISON, 1973: 9). A inicial aceitação da religião estrangeira teria sido, segundo o mesmo autor, "um fenômeno peculiar da confusa política do Sengoku [...] e os fatores que tornaram isso possível foram anulados no xogunato Tokugawa de equilíbrio político e ortodoxia intelectual" (ELISON, 1973: 2).

A missão cristã falhou, portanto, nas suas metas de evangelização do Japão. Os missionários acabaram expulsos e um número pouco significativo de japoneses permaneceram cristãos após essa interdição. Estes ainda sofreram perseguições sem poderem contar com a ajuda dos reinos cristãos ou de qualquer missionário europeu. Paradoxalmente, o significado desse século não se encontra no triunfo do Cristianismo, mas no efeito de sua derrota, uma vez que a total rejeição da religião estrangeira por parte do poder central nos dois séculos seguintes ajuda a definir a seguinte era de total isolamento (política do sakoku).

\section{Referências bibliográficas}

\section{Referências documentais}

FRÓIS, L. História de Japam, cinco volumes. Lisboa: Biblioteca Nacional de Lisboa, 1976.

GARCIA, J. M. (ed.). Cartas que os Padres da Companhia de Iesus Escreverão dos Reynos de Iapão e China aos da mesma Companhia da Índia e Europa des do anno de 1549 até o de 1580, 2 volumes. Maia: Cotovia, 1997. 
WICKI S.J., J.; GOMES S.J., J. (eds.). Documenta Indica (1592-1594), v. XVI. Roma: Institutum Historicum Societatis Iesu, 1984.

WICKI S.J., J. (ed.). Documenta Indica (1595-1597), v. XVII. Roma: Historicum Societatis Iesu, 1988.

\section{Referências historiográficas}

BOURDON, L. La Compagnie de Jésus et le Japon, Lisboa-Paris: Comission nationale pour les commemorations des decouvertes portugaises, 1993.

ELISON, G. Deus Destroyed: the Image of Christianity in Early Modern Japan, Cambridge: Cambridge Univ. Press, 1973.

EISEnberg, J. As Missões Jesuíticas e o Pensamento Político Moderno: encontros culturais, aventuras teóricas. Belo Horizonte: UFMG, 2000.

HALL, J. W. (ed.). The Cambridge History of Japan, vol. 4. Cambridge: Cambridge University Press, 1990.

JANEIRA, A. M. O Impacto Português sobre a Civilização Japonesa, Lisboa 1970.

LOUREIRO, R. M. Jesuit Textual Estrategies in Japan between 1549 and 1582. In: Bulletin of Portuguese/Japanese Studies, junho, volume 8. Lisboa: Universidade Nova de Lisboa, 2004.

MONTERO, P. (org.). Deus na Aldeia: Missionários, Índios e Mediação Cultural. São Paulo: Globo, 2006.

MORAN, J. R.. The Japaneses and the Jesuits. Alessandro Valignano in Sixteenth Century Japan, Londres, 1993.

PANIKKAR, K. M. Asia and Western Dominance, Unwin, Londres, 1967.

POMPA, M. C. Religião como Tradução: Missionários, Tupi e "Tapuia" no Brasil Colonial. Bauru: EDUSC, 2003.

PROSPERI, A. O Missionário. In: VILLARI, R. (org.). O Homem Barroco. Lisboa: Editorial Estampa, 1995.

SAMSON, G. B. Japan: a Short Cultural History. Tokyo: Charles Tuttle, 1997.

The Western World and Japan: a Study in the Interaction European Asiatic Cultures. Tokyo: Charles E. Tuttle, 1990.

TALADRIZ, J. C. A. Monumenta Nipponica Monographs. Tóquio: Sophia University, v. 9. 1954.

YAMAMURA, K. (ed.). The Cambridge History of Japan, vol. 3. Cambridge University Press, 1990.

YAMASHIRO, J. Choque Luso no Japão dos Séculos XVI e XVII. São Paulo: IBRASA, 1989. 